\title{
Nurses at the Frontline of COVID-19
}

\author{
Nada Wakim, PhD, RN, NE-BC \\ AVP of Nursing \& Case Management \\ South Miami Hospital
}

During the past few months, nurses found themselves in the midst of an unmatched and extraordinary public health crisis that rocked the globe. Yet once again, nurses proved that they are educated and prepared to face any circumstance in response to this severe and unprecedented pandemic. Nurses were ready at the frontline to face these unparalleled challenges.

Using their knowledge and competence, nurses continued to deliver the care needed, reassure and support sick and frightened patients, and serve their fearful but grateful communities. At the same time, nurses demonstrated their unequivocal sense of creativity and innovation that helped resolve a tremendous unseen amount of challenges and barriers.

Unlike everyone else, nurses had to fulfill their call of duty and remain faithful to their mission and oath. In addition to being nurses, they are also parents, siblings, friends, and partners with all the worries and concerns shared by most people - providing for and protecting their families and themselves. This weighed heavily on their shoulders.

During this difficult time, all nurses had to play a role in supporting their patients, communities, and above all, each other. Nurses are the pillar of health systems around the world, and this has never been more obvious than today. No one can doubt that nursing and healthcare will come out stronger and better prepared to face future challenges.

In the future days and months, as the effects of this pandemic fade away, we will look back and reflect upon it. We might have different thoughts about what we could have done differently and what might have been best at a certain time. However, what we all need now is to show kindness to each other and to ourselves as we struggle to adjust to our new way of living and working. I want to thank nurses everywhere and in particular across our Baptist Health South Florida entities for their tireless efforts in this unparalleled health emergency.

Let us pause, think deeply, and act persistently to build a world that is better than it was before COVID-19. Not because of the other potential pandemics of the future, but because that is the essence of responsibility and leadership. 